\title{
The Time System of the United States
}

\author{
Why It Exists and Some of Its Vagaries and Defects
}

\section{By Charles T. Higginbotham}

OUR present method of calculating and indicating time is a legacy from the ancient Romans. Having become accustomed to it through long years of use we fail to notice its shortcomings, inconsistencies, and absurdities. It is only when our attention is particularly directed to some glaring inconsistency or some
unbearable hardship that we wake up to the situation unbearable hardship that we wake up to the situation
and take measures to relieve ourselves of some burden that it imposes upon us.

Such a condition forced itself upon the attention of the public in 18s3. Previous to that year each city and town reckoned its time from its meridian. This is to say, from the meridian passing through that par. ticular place. It was impracticable for railways to ticular place. It was impracticable for railways to
arrange their time tables to conform strictly with this condition. Some attempts made to do so created considerable confusion. It necessitated the engineer and other train hands setting their watches at nearly every important station. This proved a very costly practice to the railroad companies and was the direct cause of some disasters. There were upward of fifty different kinds of railway time in the United States, and it was a usual thing for jewelry stores to provide their regua usual thing for jewelry stores to provide their regu-
lators with two minute hands, one for local time and lators with two minute hands, one for local time and
one for railway time. This caused so much inconvenione for railway time. This caused so much inconveni-
ence to the public and became such a source of trouble to railway managers that, in order to relieve the situation, an agreement was entered into to adopt four meridians from which time for the United States should be taken.

The meridians adopted for this purpose were the 75th from which Eastern time is taken. The 90th, for Central time, the 105th for mountain time, and the 120t for Pacific time. These meridians are 15 degrees apart, making a difference in time of exactly one hour between each. All the railways throughout the United State now arrange their time tables approximately in conformity with these meridians.

On November 18th, 1883, this new system went into effect and there was a general re-setting of clocks and watches all over the country. Every city and town now uses for its local time one of these meridians, th one used being identical with that used by the railway passing through, or terminating at that place.

To fully comprehend the use of these meridians it must be borne in mind that longitude is universally reckoned from Greenwich. Every sea captain all ove the world, regardless of from what port he sails or to what port he is bound, sets his chronometer by Greenwich time. It must also be borne in mind that the time occupied by the earth in making a revolution is 24 hours. Dividing 360 degrees by 24 hours gives 15 degrees; consequently 15 degrees has a time value of one hour. This is to say, the apparent motion of the sun from east to west is at the rate of 15 degrees per sun $\mathrm{f}$

The meridians, it will be understood, run north and south. The 60th, from which Atlantic time is taken, passes through the eastern parts of the province of Quebec and New Brunswick, Canada. This meridia is used on some of the Canadian railways, but is not used in the United States. The 75th meridian, from which Eastern time is reckoned, passes through Herkimer, New York, Western New Jersey and Eastern Pennmer, New York, Western New Jersey and Eastern Penn-
sylvania, about midway between Trenton and Philadelsylvania, about midway between Trenton and Philadel-
phia. The 90th meridian, from which Central time is reckoned, passes through the extreme eastern edge of Minnesota, the western part of Michigan, the center of Wisconsin; through Illinois, 17 miles west of its capital-Springfield-and 12 miles east of St. Louis, through the extreme eastern parts of Missouri and Arkansas, the extreme eastern parts of Missouri and Arkansas,
the western part of Tennessee, 3 miles east of Memthe western part of Tennessee, 3 miles east of Mem-
phis, through Mississippi, 2 miles west of Jackson, and through the eastern side of Louisiana, 5 miles east of New Orleans. The 105th meridian, from which moun tain time is reckoned, passes through eastern Montana, 40 miles east of Miles City; through eastern Wyoming, 10 miles west of Cheyenne; through Denver, and 10 miles west of Colorado Springs; through New Mexico, 50 miles east of Santa Fé; and through the extreme west of Texas, 85 miles east of El Paso. The treme west of Texas, 85 miles east of El Paso. The
120 th meridian, from which Pacific time is reckoned, passes centrally through the States of Washington and Oregon, forms the dividing line between Nevada an California, to a point 12 miles west of Carson City, thence through the center of California.

The 90th meridian furnishes time for a larger are than any other. As a matter of fact it supplies time to 55 per cent of the population of the United States.
It requires three meridians to supply the remaining 45 per cent. There are, however, confusing irregularities caused by the locations selected by the railway companies for changing their time schedules. This is un avoidable. Railways cannot be expected to change time exactly midway between meridians. They usually select the termination of divisions for that purpose As a result the Eastern and Western boundaries of the area using Central time form zigzag lines. This condition is productive of strange situations. Traveling from Greensburg, Kansas to Beverly, Nebraska-a distance of about 200 miles due north-it becomes necessary for the traveler, if he would have his watch agree with the time used in the different towns through which he passes, to set it four times during his journey. Thi is owing to his crossing the zigzag boundary lines as aid out by the railroads.

Whenever a change of time is made by a railway there must of necessity be two kinds of time at that place. At Pittsburgh they are Eastern and Central. Trains going east use the former, and those going west the latter. Buffalo has the same condition in an exaggerated form, for the reason that all trains going east use eastern time, while trains going west use both eastern and central. The Grand Trunk, the Michigan Central and the Wabash use Eastern time, while all roads south of Lake Erie use Central. Trains arrive of railway time: Central, Mountain, Pacific and Mexican. It is impossible to estimate the loss to the travel ing public from mistakes caused by this confusing state of affairs, but in stating that the monetary loss to the public from time spent in efforts to decipher and unravel the complications in our railway time tables, brough about by our present confusion system is $\$ 5,000,000$, would not seem to be very far from being correct. That this is not an exaggerated estimate may be seen when we consider that American railways carry two and a half million passengers daily. If the average loss of time in deciphering and studying time tables is one half cent per passenger the yearly aggregate would amount to $\$ 4,562,500$. In addition to this our complicated system involves increased labor and expense to the railway companies in making out their time tables. Here then we have $\$ 5,000,000$ a year absolutely wasted. Enough to build a battleship, and this lutely wasted. Enough to build a battleship, and this
does not take into account the amount lost by mistakes does not take into account the
arising from the same cause.

Another fruitful source of confusion and mistakes is the method of dividing the day and night into two periods of 12 hours, numbered, 1 to 12 , necessitating the use of those awkward and inconvenient affixes A. M. and P. M.

The Egyptians were the first to divide the day and night into 24 equal parts. They numbered the hours 1 to 24 . The Romans began their day at sunrise, numbering the hours to sunset 1 to 12 , and numbering them from sunset to sunrise also 1 to 12 . Our A. M. and P. M. is a part of the burdensome legacy inherited from them. The hours constituting their day and night were of unequal and constantly varying lengths. In course had they adopted the Egyptian method they would have had they adopted the Egyptian method they wou

The remedy for the evils we have described lies: First, in numbering the hours as the Egyptians did. Beginning, as we now do at midnight we would number the hours up to noon 1 to 12 ; the hour we now designate as $1 \mathrm{P}$. M. would be 13 , and so on to 24 . Second, we should adopt one meridian for the entire United States, which could be done without any serious disturbance of affairs. The change which was made in 1883 was hardly noticed and proved a great benefit without working hardship on anyone. The advantage secured by that change was insignificant as compared
to the advantage to be secured by the use of one to the advantage to be secure

Canada has already adopted the 24-hour system on all her railroads west of Port Arthur, and China has adopted one meridian for the entire empire, which embraces 60 degrees, the same amount as the United States. Shall we allow ourselves to be left behind by other nations?

Iet us suppose that the 90th degree-central meridian - should be adopted as the one from which United States time should be reckoned; what then would be
the effect on business? The hour of $8 \mathrm{~A}$. M. is now pretty generally adopted for the commencement of business. If we should take our time from the central meridian it would be 9 in New York, 8 in Chicago, 7 in Denver and 6 in San Francisco; but what matters it where the hands of the clock point so long as business Clocks and watches should be our servants, not we theirs.

On April 15th the sun rises at Philadelphia at 5 o'clock as we now reckon time. This is to say, the Philadelphians commence business 3 hours after sunrise. The only difference that the change would produce is that the hands of their clock would point at 9 instead of 8.

We would soon become accustomed to the proposed change and the great benefit and saving resulting therefrom would repay us many times over for any slight inconvenience that might at first be felt. With this system in force there would be no setting and resetting of traveler's or railroad employee's watches. One might travel from coast to coast without disturbing his watch. The reading of railway time tables would be so simplified that there would be no excuse for making mistakes. The absurdities that now exist in the matter of time would be eliminated

By our present system of reckoning time it would have been possible for an event to have occurred in New York on January 1st, 1911, at 1 A. M., and for that event to have been known in San Francisco at 10 P. M., December 31st, 1910. It is now possible to before you arrive from the East-according to railway time tables. The writer recently saw the apparent anomaly of two trains'standing side by side in the station at Buffalo, both headed for the West, yet the engineers' and conductors' watches on one train were just one hour ahead of the other. This sort of incongruity would be impossible with the proposed new system. Half a century ago there was not a watch in existence capable of meeting the requirements of American railway time service to-day. Railway time inspection has set the limit of variation from true time, for its employees' watches, at 30 seconds a week. This means that the balance wheel shall not vary in its motion to the extent of one vibration out of every 20,000. Taking into consideration the various causes of disturbance to which a railway engineer's watch is subjected, the jolts and jars, the changes of temperature and the magnetic influence incidental to the proximity of large masses of iron and steel, this performance is truly remarkable. That it is possible to secure such accuracy in such a tiny piece of mechanism subjected to those adverse influences is little short of marvelous, and justifies the claim that the watch of to-day is the most wonderful piece of mechanism that the ingenuity of man has ever produced.

The requirement for accuracy in railway watches in particular, and for others as well, is becoming more exacting every day. Horologists are at their wits' end to meet them. The time is surely coming when a purely mechanical.device will no longer suffice to produce sufficient accuracy. What then? Some other force of nature must be enlisted. What will it be? What else but that mysterious force, electricity? That wonderful power which is being harnessed to lighten man's burdens and minister to his wants and pleasures. Yes: Wireless Electricity is destined to solve the problem. The time is now sent out from the observatory at Washington from an astronomical clock, so protecte against all disturbing influences that it runs with infinitesimal variation, and is corrected by nightly stellar observations. Centrally located clocks controlled from this master clock at Washington will be used to send out aerial electric waves. These clocks will control a radius of, perhaps, one hundre miles. The watch and the clock of the future, like their precursors, the sun-dial and the clepsydra, will be relegated to th shelves of our museums, their places taken by electric receivers contrived to indicate time received from these cepent upon a meche res liable to error in its indications of time. He will press a button and read the time to the second, in exact conformity with the accurate astronomical clock at Washington. The little instrument which he carries will be no larger than a watch.

It may be asked: Will not the new instrument be liable to get out of order, and give incorrect time? No ! The new instrument will never lie. It may get out of order, but will never lead to a mistake. It will either Indicate correct time or no time at all, 